ISSN 2693-2490

\title{
What Does Different Personality Test and Behavioral Test Measure? and Do We Overuse Them?
}

\section{Stefan Lindstrom}

Entreprenologist. Stockholm, Sweden

\author{
*Correspondence author \\ Stefan Lindstrom \\ MBA, and Entreprenologist. \\ Stockholm \\ Sweden \\ E-mail : stefan@stefanlindstrom.com \\ Submitted : 02 Jun 2021 ; Published : 16 Jun 2021
}

Like all self-estimated and or self-assessed tests, they require that the person wants and can report truthfully about oneself.

But not so many tests that are based on or partly based on self-estimates or sometimes called self-assessed - measure congruence.

Congruence is the match between given answers among themselves. Other words that can describe congruence are conformity, uniformity, concord, dictionary of EPT test [8]

Therefore, different self-estimated tests measure this in different ways and some do not even measure it . Some testcompanies that this research has asked, has refused to answer if they measure something like consistency or reliability at all.

Beginning with the concept of tests.

What is congruence and what does it mean?

Congruence $=$ conformity, uniformity, compliance, concord, agreement. This implies a species of equivalence. As an abstract term, congruence means similarity between. The concept of congruence is generally believed to refer to personal awareness and understanding of oneself as well as one's ability to communicate that truthfully.

Response congruence $=$ This is the match between your answers among themselves. Therefore, ones answers give a probability - a likelihood of one personal response in a percentage. Like all self-estimated and or self-assessed tests, they require that the person wants and can report truthfully about oneself. The concept of congruence is generally believed to refer to personal awareness and understanding of oneself as well as one's ability to communicate that truthfully.

The term congruence is generally assumed to refer to personal awareness and understanding of oneself as well as one's ability to communicate it truthfully. I have discovered here that many self-measures use similar test scenarios to address this, which may contain a number of questions designed to measure the same thing, only formulated differently. The different phrases help to deal with misunderstandings in communication and to test for personal reliability when answering the same type of questions. Cronbach's alpha measures the reliability of the question itself but cannot determine the reliability of the person answering the question. This means that research has shown that if a person answers a question truthfully, the question can reliably measure the measured value as it is designed to measure. But what happens if the self-image is wrong or if one unknowingly answers "wrong" or responds and answers the question or even questions subconsciously to a "desired condition".

Not so many tests that are based on or partly based on selfestimates or sometimes called self-assessed - measure response congruence. That is in use to prevent or make up for unknowingly random and shifting in the test persons focus of mind and therefore answers. One test found EPT[8] measures response congruence, and in $\%$, which is rounded off in the nearest five or ten numbers. i.e., $60 \%, 70 \%, 85 \%$, etc. Another word for this Response congruence could be - Internal Consistency - which measures whether several items that propose to measure the same general construct produce similar scores. For example, if a respondent expressed agreement with the statements "I like to ride bicycles" and "I've enjoyed riding bicycles in the past", and disagreement with the statement "I hate bicycles", this would be indicative of good internal consistency (9) of the test.

Several tests refer to a Cronbach Alpha or Tau-equivalent reliability that is a single-administration test score reliability (i.e., the reliability of persons over items holding occasion fixed coefficient, commonly referred [1][2][3] to as Cronbach's alpha or coefficient alpha is the most famous and commonly used among reliability coefficients.

But recent studies recommend not using it unconditionally.[4] [5][6][7] Reliability coefficients based on structural equation 
modeling are often recommended as its alternative.

This coefficient Cronbach's alpha measures whether questions belonging to the same scale produce similar scores and so does EPT's response congruence[8] with the difference if the same question over several different contexts still from the responder is given the same answer as previous measures (inputs) and therefore the same accuracy. (This from the responder's answer.)

Cronbach's alpha measures whether questions belonging to the same scale produce similar scores. Cronbach's alpha measures the reliability of the question itself, but cannot determine the reliability of the person answering the question.

This means that research has demonstrated that should a person answer truthfully to a question, then the question can reliably measure the metric it is designed to measure. Like all self-estimated and or self-assessed tests, they require that the person wants and can report truthfully about oneself.

What is Reliability vs response congruence.

Reliability is another concept. Reliability indicates how reliable the test is. The reliability in the assessment of the archetype is how consistent the different archetypes are.

It is clear that there are some differences among the various features of the archetypes, but there are several common denominators. It is also possible that a person can move in and out of the different archetypes in different stages of his/ her development.

Reliability measures how reliable the test is in terms of distinguishing the described archetypes. It is a question of the measuring accuracy and how well the test differentiates among the archetypes. The experiences we have of the test are likely dependent on the fact that the test is most often used by people who have an orientation towards entrepreneurship. What remains to proceed with the assessment of reliability is to allow the same individuals to come back to see how consistent their answers are on different measurement occasions.

One test that does measure response congruence - EPT and its validation and reliability [8] In the EPT test it is given in \% and i.e., if the responder replays to the measured i.e.,

In 3 out of 3 or in 2 out of 3 etc it gives a different $\%$ of response congruence. Also asked several times in different situations and combinations. EPT measures response congruence, in \%, which is rounded off in the nearest five or ten numbers. i.e., $60 \%, 70 \%, 85 \%$, etc. And it the EPT's test case with response congruence the answers give a probability - a likelihood of one's personal response in a percentage. After 21 questions in 4 different surroundings, 84 questions or position statements in total.

This research also takes into account that. Since not so many test measures response congruence, it has in few cases been comment on as response congruence is in alignment with the idea of stimulus-response congruence. Claimed as, has, or would have a physical component to it that is not applicable to some kinds of test.
Another "measurement" that appears is "Face Validity" much as "'apparent" or "'obvious validity" indicates if the test at first glance appears to measure what it intends to measure.

There is no statistical or scientific in that method but can feel good and this may be important to ensure, as a test in that a person may need to perceive the test as relevant to feel motivated to take it.

Several test in a row?

It has occurred that if the client or test taker does several tests over time the congruence change and one person can therefore get a non-adequate answer. This is due to subconscious processes, and this combined with an unawareness of these phenomena.

Predispositions change the test to varying degrees. i.e., the sensitive person has a higher degree of propensity to subconsciously their responses. Liability and or insecurity of taking the test. These 3 major factors are, as yet known, that HR people should not start the recruitment process before a mutual trust has been established. i.e., post-interview. That will more lead to a more positive feeling like -you have moved on, instead of, we will check who you are - before. All this can determine the mindset of the persons doing the tests.

Several results shows that retake assessment after a break of 6 months will give similar scores.[10] [11]

\section{Conclusion}

More often than not, the first test attempt is the most accurate. If one does retest, do not retake the test too close to the previous attempt as this lends itself to overfamiliarity and overthinking the questions. In a psychology test that could lead to, for example - "Do you experience chronic feeling of emptiness"? - "No, I don't have Borderline"! - end quote

Most tests claim this overfamiliarity and overthinking and points it out. If you do retest, do not retake them too close to the previous. Some tests do not even recommend retaking the test more often than once every 6 months.

So, both the psychology test business and the test execution HR and recruitment business should be aware of this and in an ethical way not overburden the clients with continuous testings, and or for every applied job. At the same time, this leading to less accurate answers and therefore less proper use of tests.

Clients or within HR, -employees as well as jobseekers, usually seeks several jobs and then to begin every recruitment process with tests instead of ending, when really needed! That said when other major parts and pieces seems to be in place such as after $\mathrm{CV}$ reading and interviews. That process would lead to less misuse and overuse and therefore more accurate recruitments, as well as more accurate test results! 


\section{References}

1. [a b] Tavakol, Mohsen \& Dennich, Reg (2011). "Making sense of Cronbach's alpha" (på engelska). International Journal of Medical Education 2: sid. 53-55. doi:10.5116/ ijme.4dfb.8dfd. ISSN 2042-6372.

2. Cronbach, Lee J. (1951). "Coefficient alpha and the internal structure of tests" (på engelska). Psychometrika 16 (3): sid. 297-334. ISSN 0033-3123.

3. Ritter, Nicola L. (2010). "CRONBACH'S ALPHA 1 Understanding a Widely Misunderstood Statistic: Cronbach's $\alpha "$ (på engelska). Orleans: Texas A\&M University. Läst 18 december 2015.

4. Cho, E. (2016). Making reliability reliable: A systematic approach to reliability coefficients. Organizational Research Methods, 19(4), 651-682. https://doi.org/10.1177/1094428116656239

5. Cronbach, L. J. (1978). Citation classics. Current Contents, 13, 263. Green, S. B., \& Yang, Y. (2009). Commentary on coefficient alpha: A cautionary tale. Psychometrika, 74(1), 121-135. https://doi.org/10.1007/s11336-008-9098-4

6. Jump up to:a b c d e f g h Revelle, W., \& Zinbarg, R. E. (2009). Coefficients alpha, beta, omega, and the glb: Comments on Sijtsma. Psychometrika, 74(1), 145-154. https://doi.org/10.1007/s11336-008-9102-z

7. Jump up to:a b c d e f g h i j k Cho, E., \& Kim, S. (2015). Cronbach's coefficient alpha: Well known but poorly understood. Organizational Research Methods, 18(2), 207-230.https://doi.org/10.1177/1094428114555994

8. Validation \& reliability - Entrepreneur profile test

9. Internal consistency - Wikipedia

10. Q\&A - Entrepreneur profile test

11. Is It Possible to Change Your Personality Type? 16Personalities

Other sources about Cronbach alpha

1. McNeish, D. (2017). Thanks coefficient alpha, we'll take it from here. Psychological Methods, 23(3), 412-433. https://doi.org/10.1037/met0000144 pos

2. Jump up to:a b c Raykov, T., \& Marcoulides, G. A. (2017). Thanks coefficient alpha, we still need you! Educational and Psychological Measurement, 79(1), 200-210. https://doi.org/10.1177/0013164417725127

Personality Type Indicator (my-personality-test.com)

Free personality test, type descriptions, relationship and career advice | 16Personalities

Reliability and Validity | 16Personalities

General about International Personality Item

IPIP Home(https://ori.org/)

Copyright: (C2021 Stefan Lindstrom. This is an open-access article distributed under the terms of the Creative Commons Attribution License, which permits unrestricted use, distribution, and reproduction in anymedium, provided the original author and source are credited. 